\title{
Should psychiatric trainees do research?
}

\author{
Chris Williams and Stephen Curran
}

Freeman (1992) advocated the setting up of a network of College Research Training Coordinators to provide practical assistance and supervision for trainees engaging in research for the first time. A recent debate held at a College Research Training Coordinators meeting in York under the Chairmanship of Dr Chris Freeman debated the motion "All trainees should undertake research". This has stimulated us to think again about our own attitudes towards this question.

Ambivalent feelings often arise when trainee psychiatrists begin to think about getting involved in research. Many have found that their medical school training has left them ill prepared to think or question clinical practice. Medical training is now changing; the General Medical Council (GMC, 1993) has advocated that more emphasis be placed on problem and evidencebased learning. Students are encouraged to question why doctors do what we do. Does this questioning attitude continue after qualification?

It is our experience that for the first year or so in psychiatric practice, trainees rightly tend to focus on learning the skills of clinical assessment and diagnosis, and on passing the Part I MRCPsych exam (Ferran, 1993). After the exam,. junior staff may want to 'stretch' themselves both clinically and academically. This is reinforced by the change in emphasis in the Royal College examinations which appear to be more factual in Part I: by contrast, the Part II exam also encourages candidates to question the evidence on which they base their practice, and seems to place more emphasis on whether the candidate possesses the skills and knowledge of a 'good' psychiatrist. This emphasis highlights the obvious benefits of evidence-based clinical decision making in the treatment of patients as advocated by the Cochrane initiative (Haines \& Iliffe, 1995).

Questioning attitudes are ones that logically lead towards research, yet junior members of staff are often put off exploring their clinical practice in this way. Sometimes this can almost amount to a 'Research phobla'. Research becomes the ' $R$ ' word, and there can be appreciable peer pressure against becoming involved. Even among insightful psychiatrists, such social pressures to conform may be potent.
Juniors therefore quite often have ambivalent feelings about research. The positive aspects of research may be muddied by other mixed mottvations (doing the research for others rather than for oneself, job references and the desire to have a publication on one's $\mathrm{CV}$ ).

What are the advantages and possible disadvantages of developing research skills? We have summarised these in Table 1.

Much of the best research stems from interesting clinical observations or questions. Good research skills, like good clinical skills require time, practice and supervision to develop. Most approved psychiatric training schemes encourage trainees to gain these skills with provision of a postgraduate course which will often include a research component. Senior registrars in psychiatry have both a 'Special interest' day to develop further their clinical experience, and a research day to develop their research skills.

One question that must be asked is "What is research?" It would be a useful starting point for the Royal College to define the sort of research which it feels is important for trainee psychiatrists to experience. If research is defined narrowly as meaning some high powered biological investigation or the 'gold-standard' placebocontrolled randomised double-blind trial, then we would suggest that this is something that most trainees should avold, and certainly before senior registrar level. These styles of research are probably best left to more senior researchers or clinicians who have a clear research focus which they have pursued over some years. What 'research' then should senior house officers and registrars undertake? We would advocate that junior staff at pre-senior registrar level should be encouraged to become involved in small scale research projects such as surveys, writing a case report, or carrying out an audit. This can be supervised and encouraged by a more senior and experienced colleague, but the interest and enthusiasm must come primarily from the trainee. It is vitally important that the trainee wants to do the project and feels motivated. It should include a simple hypothesis, and be achievable within six months to a year. 
Table 1. The research dilemma faced by junior doctors

\begin{tabular}{|c|c|}
\hline Beneitts of resecorch & Dilliculties undertaking resecarch \\
\hline Can be very interesting, rewarding and creative. & $\begin{array}{l}\text { Balancing competing clinical and other demands in } \\
\text { busy jobs with other pressures, e.g. to pass exams. }\end{array}$ \\
\hline $\begin{array}{l}\text { Leam new skills as the project is designed (research } \\
\text { design, writing protocols, data analysis, being able } \\
\text { to think clearly and seek answers to specific questions). }\end{array}$ & $\begin{array}{l}\text { Problems obtaining helpful/supportive advice from } \\
\text { experienced colleagues. Sometimes a fear that the } \\
\text { inexperienced trainee will end up doing all the } \\
\text { hard work. }\end{array}$ \\
\hline $\begin{array}{l}\text { Increase knowledge base in a focused area. This can } \\
\text { be useful for exams or clinical practice. }\end{array}$ & $\begin{array}{l}\text { SHOs and registrars often have no formalised time } \\
\text { specifically put aside for research. }\end{array}$ \\
\hline $\begin{array}{l}\text { Clinical knowledge of topic, statistical and } \\
\text { methodology knowledge helpful in exams. }\end{array}$ & $\begin{array}{l}\text { Practical difficulties (lack of secretarial support, no easy } \\
\text { access to computers, etc.). }\end{array}$ \\
\hline $\begin{array}{l}\text { Abillty to work independently and as part of a team. } \\
\text { Develop management and leadership skills. }\end{array}$ & $\begin{array}{l}\text { Fear of research. Research is seen as hard and boring. } \\
\text { Peer pressure against research can lead to a fear of } \\
\text { social rejection. }\end{array}$ \\
\hline Develop writing and presentation skills. & $\begin{array}{l}\text { Lack of skills in research methodology and therefore not } \\
\text { knowing how to start. }\end{array}$ \\
\hline Improved organisational skills. & Lack of financial support. \\
\hline $\begin{array}{l}\text { Leam how to use library facilities/carry out a literature } \\
\text { review. }\end{array}$ & $\begin{array}{l}\text { No-one to set deadlines and encourage to keep to } \\
\text { them. }\end{array}$ \\
\hline $\begin{array}{l}\text { Develop skills in the use of new technology/computer } \\
\text { data analysis and word processing packages. }\end{array}$ & $\begin{array}{l}\text { Motivation: Who is the research for? Mottvation will be } \\
\text { less if it is percelved that the work is being done for } \\
\text { someone else. }\end{array}$ \\
\hline $\begin{array}{l}\text { Develop skills to critically evaluate research that has } \\
\text { been carried out and determine its relevance to clinical } \\
\text { practice. Focus on evidence-based practice. }\end{array}$ & $\begin{array}{l}\text { Discouragement that sets in if findings are rejected by } \\
\text { joumals. }\end{array}$ \\
\hline
\end{tabular}

We have been involved in using this approach within a 'Juniors-only' Research Club, which has run at St James's Hospital for over a year. It meets once a month and lasts for 90 minutes. Only staff at senior registrar level or below are allowed to attend, and this aims to defuse feelings of tension or stress that might otherwise be felt. The provision of a sponsored lunch encourages an informal atmosphere. A cycle of meetings is held every six months. This includes an introductory meeting that outlines the fact that research can be interesting, relevant and achievable in only limited time. Presentations are made by peers who are currently carrying out some small project, and small group work is then used to brainstorm potential interesting research ideas.

The junior doctors who come can choose to work individually or as part of a small group. By the end of the second meeting, each small group is encouraged to go away to gather more information (e.g. by requesting one of the three free literature reviews offered by the Royal College Library staff to Inceptors and College members) and to write a protocol, usually 1-3 sides of A4 paper. These are then presented to the group for constructive criticism at the next Club meeting. Attendance has been very good with over threequarters of junior staff attending on a completely voluntary basis. With this approach, we believe that enthusiastic research is encouraged, which can lead to the person wanting to take the questions they have asked further, perhaps in the form of the longer and more intenstve research component of a postgraduate course which is offered as part of the local psychiatric rotation. This allows the postgraduate degree to be seen in context as an interesting and helpful way of integrating academic, clinical and research skills in a way which complement each other.

It is our belief that junior psychiatrists should be aiming to carry out research at this sort of level, allowing them to gain real skills and confidence. For a minority, this may lead on to a full-time research job, but for most, the skills learnt will be a useful adjunct to their clinical experience, and will help them to become more questioning doctors.

One final comment. The recent debate by the College Research Training Coordinators meeting voted against the motion "All trainees should undertake research" by a large majority. We agree, but with some reservations. The term 'research' should be kept to describe the focused longer-term 'gold-standard' research projects. We suggest that for trainees it be replaced by the term 'clinical project'. This would involve carrying out and writing up material at the level of case 
reports or small surveys which are achievable within 6-12 months requiring minimal resources. This is the first step in helping trainees think and work critically in their clinical practice. There is, however, always the possibility that this would lead the ' $R$ ' word to be replaced by the 'P' word!

\section{Acknowledgement}

We wish to thank Professor A. C. P. Sims, Professor of Psychiatry, University of Leeds for his helpful comments on this paper.

\section{References}

BARTLeTt, A. E. A. \& DRUmmond, L. M. (1992) The problem with Registrar research. Psychiatric Bullettin, 16. 361362.
FerRan, J. (1993) Publish or perish? Psychiatric Bullettn, 17. 374.

FREEMAN, C. (1992) The research committee's proposal for research tutors. Psychiatric Bullettr, 16, 57-59.

GenERAl Medical CouncL (1993) Tomorrow's Doctors. Recommendations on Undergraduate Medical Education. London: General Medical Councll.

HAINES, A. \& IUFFE, S. (1995) Innovations in services and the appliance of science. Brttish Medical Joumal, 310. 815-816.

*Chris Williams, Lecturer in Psychiatry, Level 5 CSB, St James's University Hospital, Beckett Street, Leeds LS9 TTF; and Stephen Curran. Lecturer in Psychiatry, St James's Hospital, Leeds LS9 TTF

*Correspondence

\section{Seminars in Practical Forensic Psychiatry}

\section{Edited by Derek Chiswick \& Rosemary Cope}

Seminars in Practical Forensic Psychiatry is a concise account of the specialty from a strongly practical perspective. It systematically describes the relationship between psychiatric disorders and offending, with detailed discussion of the criminal justice system, court proceedings, mental health legislation, dangerousness, prison psychiatry, and civil issues. There are boxes summarising key points, illustrative case examples, and sample court reports. It is up-to-date, with references to the Reed Report, the Clunis Inquiry, supervision registers and recent legislation. Career guidance and a chapter on ethical issues are included. This book will be invaluable for general psychiatrists and for trainees in forensic psychiatry, as well as those other health and social work professionals having contact with mentally disordered offenders, and those who are part of the criminal justice system.

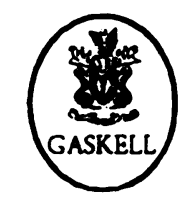

$\bullet £ 17.50 \bullet 359 p p . \bullet 1995 \bullet$ ISBN 0902241788

Available from bookshops and from the Publications Department,

Royal College of Psychiatrists, 17 Belgrave Square, London SW1X 8PG (Tel. 0171-235 2351) 